\title{
Lowering the $\mathrm{C}-\mathrm{H}$ Bond Activation Barrier of Methane Using SAC@Cu(111): A Periodic DFT Investigations
}

\author{
Meema Bhati, ${ }^{\dagger} \ddagger$ Jignesh Dhumal, ${ }^{\dagger}$ and Kavita Joshi*,†, \\ $\dagger$ Physical and Materials Chemistry Division, CSIR-National Chemical Laboratory, Dr. \\ Homi Bhabha Road, Pune-411008, India. \\ $\ddagger$ Academy of Scientific and Innovative Research (AcSIR), Ghaziabad-201002, India. \\ E-mail: k.joshi@ncl.res.in
}

\begin{abstract}
Methane has long captured the world's spotlight for being the simplest and yet one of the most notorious hydrocarbon. Exploring its potential to be converted into valueadded products has raised a compelling interest. In the present work, we have studied the efficiency of Single-Atom Catalysts (SACs) for methane activation employing Density Functional Theory (DFT). The Climbing Image-Nudged Elastic Bond (CI-NEB) method is used in tandem with the Improved Dimer (ID) method to determine the minimum energy pathway for the first $\mathrm{C}-\mathrm{H}$ bond dissociation of methane. Our study reported that the transition-metal doped $\mathrm{Cu}(111)$ surfaces enhance adsorption, activate $\mathrm{C}-\mathrm{H}$ bond, and reduce activation barrier for first $\mathrm{C}-\mathrm{H}$ bond cleavage of methane. The results suggest $\mathrm{Ru} / \mathrm{Co} / \mathrm{Rh}$ doped $\mathrm{Cu}(111)$ as promising candidates for methane activation with minimal activation barrier and less endothermic reaction. For these SACs, the calculated activation barriers for first $\mathrm{C}-\mathrm{H}$ bond cleavage are $0.17 \mathrm{eV}, 0.24 \mathrm{eV}$, and
\end{abstract}


$0.26 \mathrm{eV}$ respectively, which is substantially lower than $1.13 \mathrm{eV}$, the activation barrier for $\mathrm{Cu}(111)$.

\section{Introduction}

Earth is home to rich reserves of methane, making it an attractive feedstock and a foremost competitor for the production of green fuel.1 The myriad occurrence of methane can be attributed to its stable nature. Higher symmetry (Td) along with close shell electronic configuration, wide HOMO-LUMO gap $(\approx 8.9 \mathrm{eV})$, and four stable $\mathrm{C}-\mathrm{H}$ bonds $\left(\mathrm{E}_{b d} \approx 4.5 \mathrm{eV}\right)$, makes it thermodynamically and kinetically stable at room temperature. Given the significant mass percentage of hydrogen $(25.13 \%)$ in methane, it is widely used for hydrogen production. ${ }^{2}$ Steam Methane Reforming (SMR) and Fischer-Tropsch (FT) synthesis are widely used processes for conversion of methane to hydrogen as well as to value-added products like methanol, formic acid, formaldehyde, higher hydrocarbons, and FT fuels. However, stability of methane makes it resistant to electrophilic and nucleophilic attacks. For most methane conversion reactions, the first $\mathrm{C}-\mathrm{H}$ bond cleavage is the primary and the rate-limiting step. This motivates the rational design of a catalyst aiming at reducing the activation barrier for C-H bond dissociation.

Planar and stepped nickel surfaces are go-to catalysts used industrially in the aforementioned processes, primarily because $\mathrm{Ni}$ is procured at cheap rates and portrays excellent reactivity towards methane. The drawback of Ni catalysts is that they can completely dehydrogenate methane into carbon and hydrogen, which causes coking. Nullifying or preventing coking in methane conversion reactions is challenging area of current research. $\frac{314}{4}$ The literature cites multiple studies in both theoretical and experimental verticals across various catalyst classes discussing methane activation. For example, it has been investigated on supported metal clusters, ${ }^{[5}$ noble metal surfaces, ${ }^{6-9}$ mixed-metal alloys, $\frac{10}{20}$ zeolites, $\frac{11}{11}$ metalorganic frameworks(MOFs), $\frac{12}{2}$ metal oxides, $\frac{13,15}{15}$ perovskite, $\frac{16}{16}$ and supported single-atom 
catalysts $(\mathrm{SACs})^{17}$ to name a few. Lately, SACs have emerged as a focal point in active research surrounding methane activation. ${ }^{13[16 \mid 18}$ Doping the base metal with a single atom increases the number of active sites on the surface, thus reducing the use of precious metals as traditional catalysts. SACs, as an interesting class of catalyst subtly modify the electronic structure of the base metal and the dopant itself. This unique alteration of properties is a consequence of changing the atomic environment and dopant-doped interaction. Pt doped rutile $\mathrm{TiO}_{2}(110)$ catalyst $\left(\mathrm{E}_{a d s}=-0.62 \mathrm{eV}, \mathrm{E}_{a c t}=0.15 \mathrm{eV}\right)^{13}$ and Ag-doped $\mathrm{CeO}_{2}(100)\left(\mathrm{E}_{a d s}=-1.01\right.$ $\left.\mathrm{eV}, \mathrm{E}_{\text {act }}=0.21 \mathrm{eV}\right)^{14}$ have shown considerable activity in terms of bondlength activation, adsorption energy, and activation barrier. $\operatorname{IrO}_{2}(110)$ activates methane at low temperature, 19 and $\mathrm{IrO}_{2}$ nanoparticles activate it at temperatures as low as $110^{0} \mathrm{C} \cdot \stackrel{20}{\mathrm{Pt}} \mathrm{PSrBO}_{3}(100)$ surfaces (where $\mathrm{B}=\mathrm{Ti}, \mathrm{V}$, and $\mathrm{Cr}$ transition metals) chemisorb methane dissociatively, ${ }^{16}$ are also some prominent examples from the literature.

The work presented here is focused on the study of methane activation, in particular the adsorption, $\mathrm{C}-\mathrm{H}$ bond elongation, and the $\mathrm{C}-\mathrm{H}$ bond dissociation over several $\mathrm{M} @ \mathrm{Cu}(111)$. The Transition State (TS) analysis is performed for potent SACs where maximum bond elongation and adsorption is observed, using the CI-NEB and ID method. The metal atom interacts weakly with $\mathrm{CH}_{4}$ molecule if it's d-orbitals are filled, whereas strong interaction occurs when d-orbitals are partially filled. $\mathrm{Ru}, \mathrm{Co}$, and $\mathrm{Rh} / \mathrm{Cu}(111)$ show better chemical reactivity towards methane dissociation, where activation barrier is found to be much lower than that of $\mathrm{Cu}(111)$ surface. Our calculations provide atomic level insights into the mechanism of methane activation on SACs, and identify $\mathrm{Ru} / \mathrm{Co} / \mathrm{Rh}$ doped $\mathrm{Cu}(111)$ as a potent catalyst for first $\mathrm{C}-\mathrm{H}$ bond dissociation.

\section{Computational Details}

Kohn-Sham Formalism of Density Functional Theory (DFT) is employed to carry out all the calculations. Projector Augmented Wave potential is used, 21222 with Perdew-Burke- 
Ernzerhof (PBE) ${ }^{23}$ approximation for the exchange-correlation and generalized gradient approximation $^{24}$ as implemented in plane-wave, pseudopotential based code, Vienna Ab-initio Simulation Package (VASP) ${ }^{25}+27$ Within our framework, the calculated value of the lattice constant for $\mathrm{Cu}$ is found to be $3.62 \AA$ which is in agreement with the experimental value of $3.61 \AA .28$ Atomic Simulation Environment (ASE) ${ }^{29}$ is used to cleave $\mathrm{Cu}(111)$ surface. We substituted one of the $\mathrm{Cu}$ surface atom with the dopant to model the SACs under investigation. We used a 3x3x4 supercell with a 5x5x1 Monkhorst Pack grid resulting into 13 K-points in the IBZ for primary screening of twenty-two SACs towards methane adsorption. The k-points convergence exercise was carried out by increasing the Monkhorst-Pack grid for each system. It was observed that the difference in energies was less than $4 \mathrm{meV} /$ atom for every system. Ten potential candidates were then investigated for first $\mathrm{C}-\mathrm{H}$ bond cleavage, in a $4 \times 4 \times 4$ supercell with a $3 \times 3 \times 1$ Monkhorst Pack grid. Our calculations reported that a change in system setup is not associated with any observable changes in adsorption energies and bondlength activation. $24 \AA$ of vacuum is found to be sufficient to avoid interaction between adjacent images of planes along the z-direction. The criteria of a force cutoff of 0.01 $\mathrm{eV} / \AA$ on the unfixed atoms and the total energy convergence below $10^{-5} \mathrm{eV}$ for each SCF cycle are employed for geometry optimization. The Van der Waals corrections are applied to all the calculations. The adsorption energy $\left(\mathrm{E}_{a d s}\right)$ is calculated as, $\mathrm{E}_{a d s}=\mathrm{E}_{\text {slab+methane }}$ $\left(\mathrm{E}_{\text {slab }}+\mathrm{E}_{\text {methane }}\right)$; where $\mathrm{E}_{\text {slab+methane }}$ is the energy of the system when methane is placed on the slab, $\mathrm{E}_{\text {slab }}$ is the energy of the bare slab, $\mathrm{E}_{\text {methane }}$ is the energy of the methane molecule. A negative value of $\mathrm{E}_{a d s}$ indicates an exothermic chemisorption process. Methane decomposition $\left(\mathrm{CH}_{4} \rightarrow \mathrm{CH}_{3}+\mathrm{H}\right)$ reaction is studied by employing Climbing Image - Nudged Elastic Band (CI-NEB) method ${ }^{30}$ and Improve Dimer (ID) method ${ }^{3132}$ and activation barriers are reported. Three images are considered for TS calculations using a force convergence of 0.1 $\mathrm{eV} / \AA$. The transition state structure is confirmed by vibrational frequency analysis, and zero point energy correction is applied in all the cases. Projected Density of States ( $p D O S)$ are calculated with denser k-mesh using LOBSTER ${ }^{33+36}$ to understand the site-specific ad- 
sorption pattern. Finally, Mulliken charges are calculated for all the atoms on the surface, providing insights into the quantitative charge transfer.

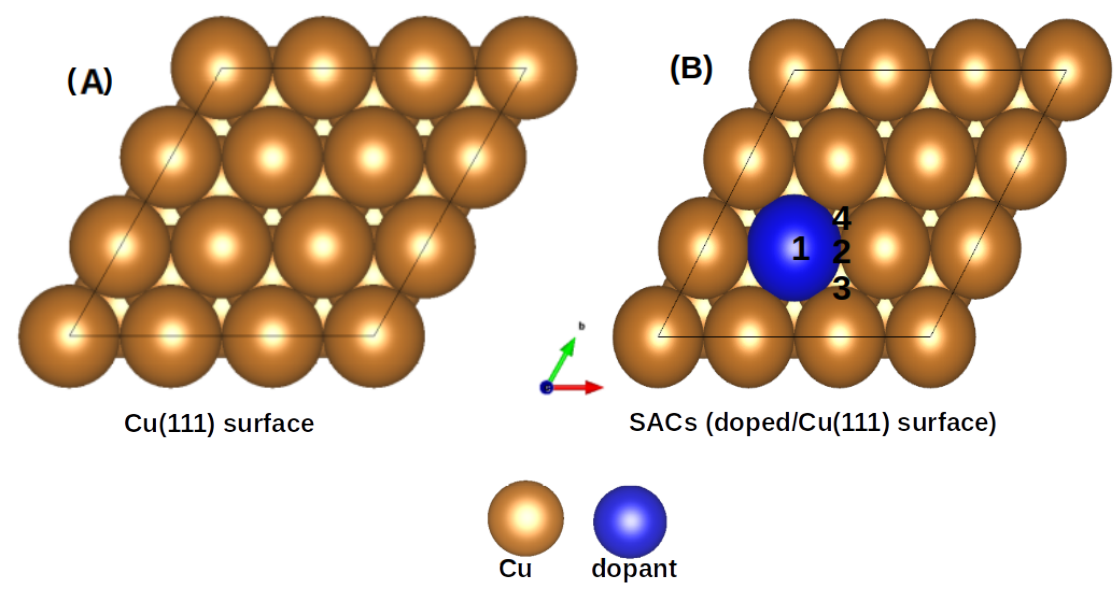

Figure 1: Top view of the unit cells: (a) $\mathrm{Cu}(111)$, (b) $\mathrm{TM} / \mathrm{Cu}(111)$ surface. 1,2,3, and 4 represent the unique adsorption sites

\section{Results and discussions}

Copper is an economically viable resource, while its (111) facet is naturally abundant. Our choice of copper as the base metal largely revolved around the fact that it prevents overoxidation of products, portrays improved selectivity, and is resistant to coking. Twenty-two dopants are doped on a $\mathrm{Cu}(111)$ model system. The dopants chosen are well studied and are known to form alloys with copper. $\frac{37}{37}$ The single-atom site was alloyed in $\mathrm{Cu}(111)$ surface to create a Single-Atom Catalyst (SAC). Eighteen of the dopants belong to transition metals vis-a-vis; Ti, V, Cr, Mn, Fe, Co, Ni, Zn of 3d series, Zr, Mo, Tc, Ru, Rh, Pd, Ag from $4 \mathrm{~d}$ series, and $\mathrm{Ir}, \mathrm{Pt}, \mathrm{Au}$ belonging to $5 \mathrm{~d}$ series. The remaining four $\mathrm{Al}, \mathrm{Mg}, \mathrm{Pb}$, and $\mathrm{Bi}$ are non-transition metals. SACs doped with non-transition metals do not show $\mathrm{C}-\mathrm{H}$ bond activation and hence the results and discussions henceforth only include TM@Cu(111). Four unique adsorption sites are recognized for methane adsorption on the SACs and are shown in Fig. 1. Adsorption of methane on SACs is analyzed based on $\mathrm{C}-\mathrm{H}$ bond elongation, variation 
in bond angles, alterations to M-C bondlength, and adsorption energies.

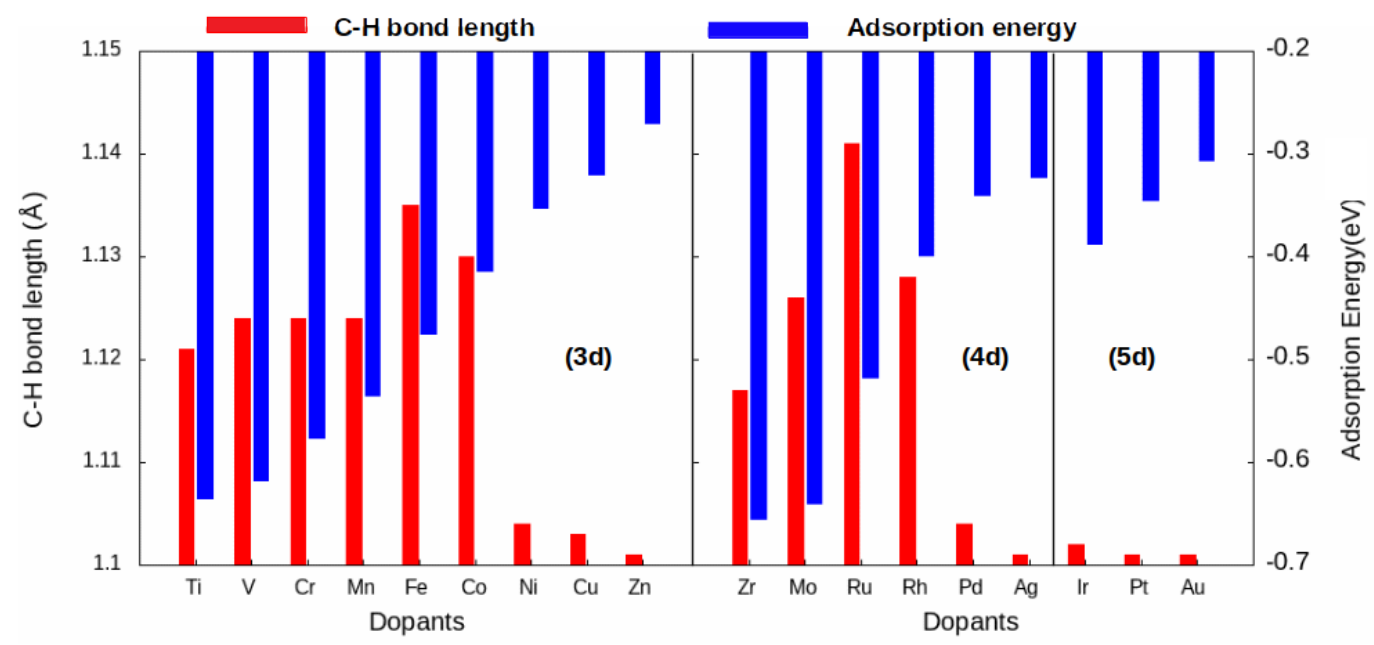

Figure 2: $\mathrm{C}-\mathrm{H}$ bondlength activation (red, left y-axis) and adsorption energies (blue, right $\mathrm{y}$-axis) are plotted as a function of dopant. Correlation between adsorption energies and group of the dopant is obvious. However, same is not true for $\mathrm{C}-\mathrm{H}$ bond activation.

The study revealed that the most stable adsorption site for methane on TM doped SACs is on the top of the dopant atom. Further, when placed at other sites, methane slides towards the dopant atom after structural optimization. Methane interacts with the partially filled d-bands of the dopant more effectively as compared to the $\mathrm{Cu}$ atoms with filled $\mathrm{d}$ band. For all SACs, as we move from left to right of the periodic table, adsorption energy decreases as evident from Fig. 2. However, such a correlation is missing in case of the C-H bondlength elongation. Also, there is no visible one to one correlation between adsorption energies and $\mathrm{C}-\mathrm{H}$ bond elongation. For all the studied SACs, the range of adsorption energy varies from $-0.32 \mathrm{eV}$ to $-0.74 \mathrm{eV}$, and the $\mathrm{C}-\mathrm{H}$ bondlength elongation scales from $1.101 \AA$ to 1.141 Aas summarized in SI Table 1. Considering Metal-C bondlength and accompanied adsorption energies, we define physisorption at the energy range of $-0.10 \mathrm{eV}$ to $-0.35 \mathrm{eV}$ and chemisorption at an energy range from $-0.35 \mathrm{eV}$ and below (as shown in SI Fig. 1 (A and B)). 
Adsorption energy decreases across the period with increasing metal-carbon bondlength as depicted in SI Fig. 1-B. Thus, methane-SAC interactions are dominated by the size, electronegativity, and empty d-states of the dopant atom. Methane is physisorbed on late-transition metal-doped SACs, whereas it is chemisorbed on early-transition and midtransition metal-doped SACs. Within this range of chemisorption, methane interacts relatively strongly with SACs doped with early-transition metals. This can be attributed to their less electronegativity, more empty d-bands, and large atomic size of the dopant atom. Consequentially, the early-transition metals form metal carbides. $\frac{38}{2}$ Eight of the eighteen transition metals doped SACs reported an elongation of about $3 \%$ to $5 \%$ in the $\mathrm{C}-\mathrm{H}$ bond compared to the physisorption on pure $\mathrm{Cu}(111)$ surface.
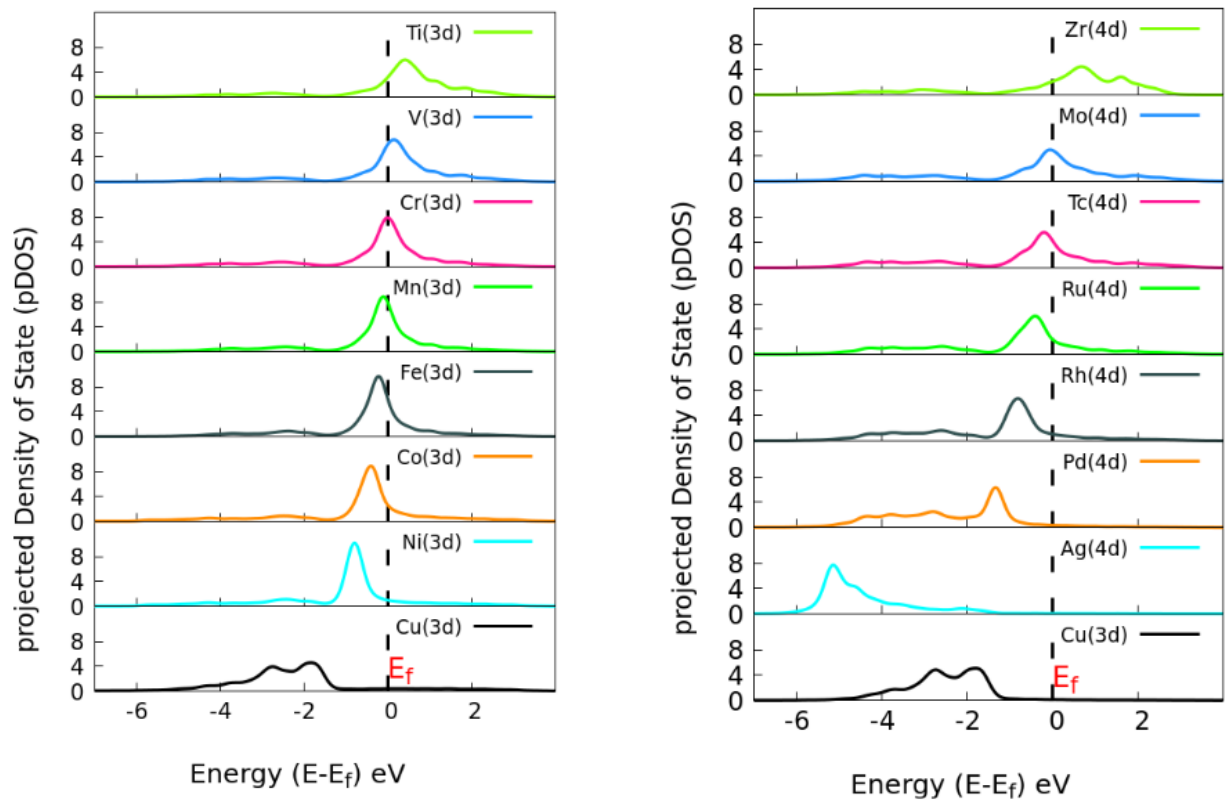

Figure 3: Site specific $p D O S$ of various TM doped $\mathrm{Cu}(111)$ SACs. pDOS for elements with filled d-band lie below Fermi level whereas for SACs with incomplete d-band are near Fermi.

Next, we analyzed the pDOS of bare SACs and $\mathrm{Cu}(111)$ surfaces, explaining the increased charge transfer in SACs per the dopant atoms. Copper, having it's d-states filled, shift towards lower energy whereas SACs with partially empty d-band lie near the Fermi level, as evident from the pDOS of the hybridized energy states shown in Fig. 3. Our observations are in line with the d-band center theory, which dictates that the systems with the d- 
band center lying near the Fermi level are catalytically more active. ${ }^{39}$ Once doped, there is charge redistribution on surface atoms, reported by quantitative Mulliken charge analysis as mentioned in SI Tab. 2.

Interaction between methane and SACs describing the charge transfer from the surface to methane molecule as reported in SI Tab. 2, could be understood from pDOS plotted with respect to vacuum and shown in Fig. 4. For isolated methane, $\mathrm{C}(2 \mathrm{p})$ peak is sharp with the highest intensity. $\mathrm{C}(2 \mathrm{p})$ peak of physisorbed methane is same in nature but with reduced intensity. $\mathrm{C}(2 \mathrm{p})$ peak of chemisorbed methane is shown for two cases, the most activated one $(\mathrm{Ru} / \mathrm{Cu}(111))$ and the most stable one $(\mathrm{Mo} / \mathrm{Cu}(111))$. Not only the peak intensity decreases but also the broadening of the peak along with a secondary peak is observed in both the cases as evident from Fig, 4. In addition, our study revealed that the mid-transition doped SACs show more $\mathrm{C}-\mathrm{H}$ bond activation.
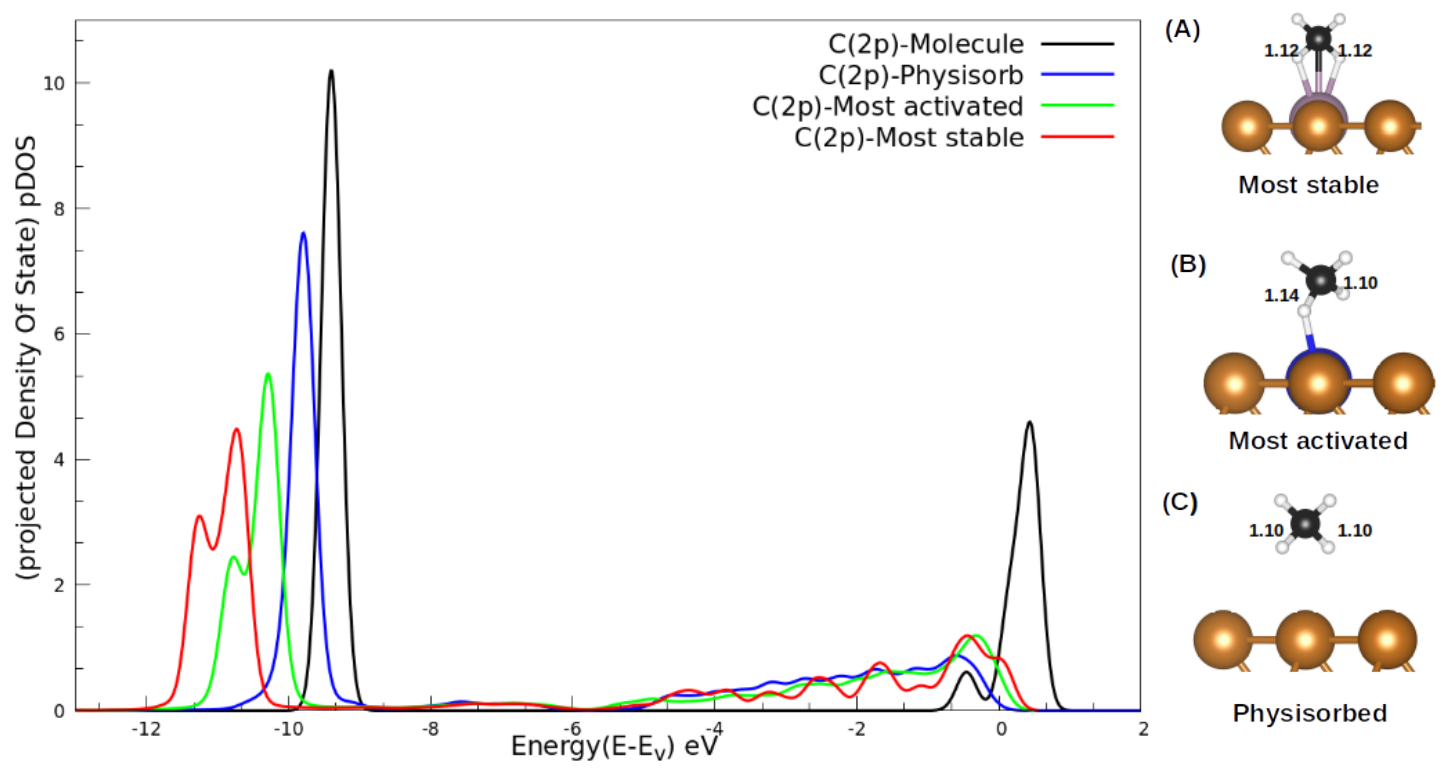

Figure 4: $p D O S$ for $\mathrm{C}(2 \mathrm{p})$ state of methane with respect to vacuum; for molecular (black), physisorbed (blue), most activated (green), and most stable (red). Side panel: (A-C) side view of methane adsorbed on SACs, where copper color is used for $\mathrm{Cu}$, blue for $\mathrm{Ru}$, purple for $\mathrm{Mo}$, white for $\mathrm{H}$ and black for the carbon atom

Cleavage of the first $\mathrm{C}-\mathrm{H}$ bond in $\mathrm{CH}_{4}$ is a primary and rate determining step for methane conversion towards most value-added products. The SACs which reported a bond elonga- 

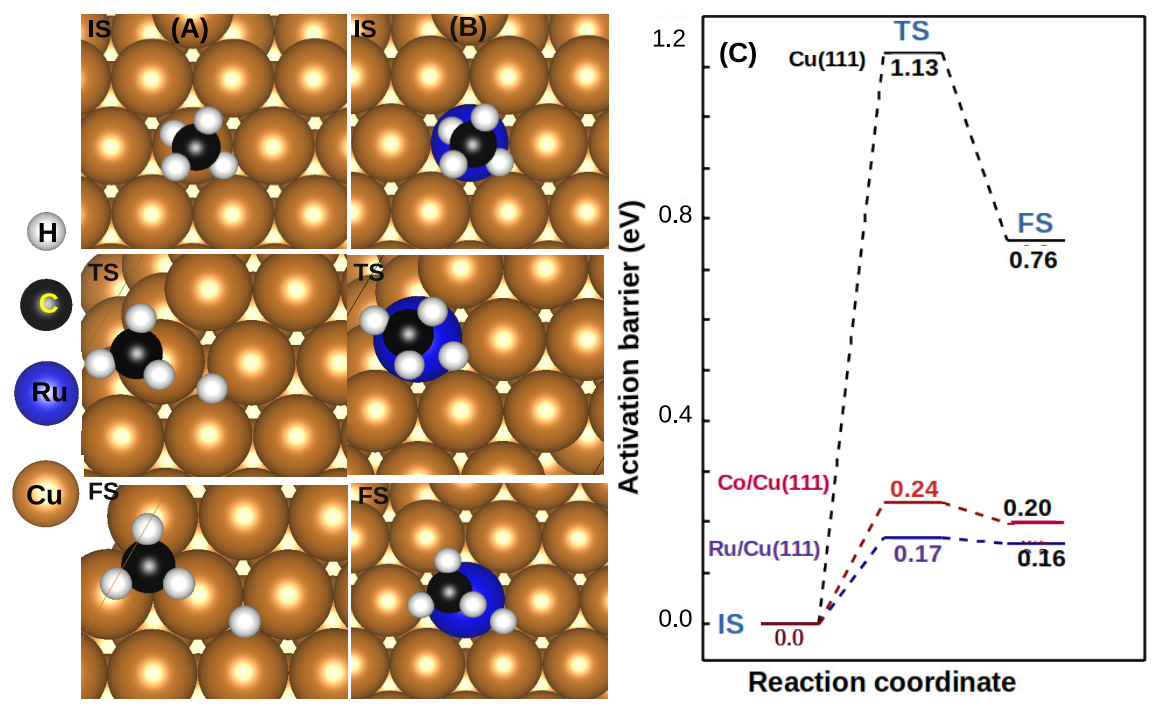

Figure 5: Top view of molecular adsorption (IS), Transition state (TS), and dissociative adsorption(DA/FS) configurations of $\mathrm{CH}_{4}$ on: (A) $\mathrm{Cu}(111)$ surfaces, (B) $\mathrm{Ru}_{1} / \mathrm{Cu}(111) \mathrm{SACs}$. Copper, blue, black, and white balls indicate $\mathrm{Cu}, \mathrm{Ru}, \mathrm{C}$, and $\mathrm{H}$ atoms, respectively. Free energy profile of first $\mathrm{C}-\mathrm{H}$ bond dissociation of $\mathrm{CH}_{4}$ on $\mathrm{Ru}, \mathrm{Co} / \mathrm{Cu}(111)$, and $\mathrm{Cu}(111)$ surfaces.

tion of about $3 \%-5 \%$ were selected to study dissociative adsorption (DA) of methane. The dissociative adsorption of methane $\left(\mathrm{CH}_{3}+\mathrm{H}\right)$ on $\mathrm{Cu}(111)$ surface is found to be thermodynamically unfavorable, whereas it is favorable for the SACs. For all the cases studies, dissociation of methane is an endothermic phenomenon, and the values are reported in Table 1. We observed that the lowest activation barrier is accompanied with the most elongated $\mathrm{C}-\mathrm{H}$ bond. When methane adsorbed strongly, the activation barrier is higher as a result of the formation of a stable configuration (C-M-H sigma complex) as shown in Fig.4 A. Typical configurations of the IS, TS, and FS in case of $\mathrm{Cu}(111)$ and $\mathrm{TM} @ \mathrm{Cu}(111)$ are shown in Fig. 5. and the relevant data is summarized in Table 1. The ZPE correction is important for C-H bond due to it's large vibrational frequency. Computed ZPE for all the SACs is in range of 0.187 to $0.191 \mathrm{eV}$, which is in agreement with the experimental $(0.21 \mathrm{eV})$ value. Marcinkowski et al. ${ }^{40}$ reported the value for $\mathrm{C}-\mathrm{H}$ bond activation on $\mathrm{Cu}(111)$ surface, $\mathrm{E}_{\text {ads }}$ $-0.38 \mathrm{eV}$, with reaction barrier of $1.4 \mathrm{eV}$, which is similar to our results, $\mathrm{E}_{a d s}=-0.34 \mathrm{eV}$, $\mathrm{E}_{a c t}=1.32 \mathrm{eV}$. Coiobica et al. ${ }^{41}$ reported that on pure $\mathrm{Ru}(0001)$ surface the barrier for first $\mathrm{C}-\mathrm{H}$ bond dissociation is $0.88 \mathrm{eV}(85 \mathrm{~kJ}$ mol-1) for the physisorbed methane. Interestingly, 
Table 1: C-H bond activation, M-C bondlength, corresponding adsorption energy (eV) and activation energy for $\mathrm{TM} / \mathrm{Cu}(111)$ surfaces, $\mathrm{E}_{\text {act }}$ with zero point correction and reaction energy

\begin{tabular}{ccccccc}
\hline Dopant(TM) & $\mathrm{b}_{C-H}(\AA)$ & $\mathrm{b}_{M-C}(\AA)$ & $\mathrm{E}_{a d s}(\mathrm{eV})$ & $\mathrm{E}_{\text {act }}$ & $\mathrm{E}_{\text {act }}(\mathrm{ZPC})$ & $\mathrm{E}_{\text {rec }}(\mathrm{eV})$ \\
\hline \hline $\mathrm{Cu}$ & 1.103 & 3.0 & -0.31 & 1.32 & 1.13 & 0.73 \\
$\mathrm{Ti}$ & 1.121 & 2.51 & -0.63 & 0.51 & 0.32 & 0.06 \\
$\mathrm{~V}$ & 1.124 & 2.46 & -0.61 & 1.33 & 1.14 & 0.22 \\
$\mathrm{Fe}$ & 1.135 & 2.45 & -0.47 & 0.67 & 0.48 & 0.11 \\
$\mathrm{Co}$ & 1.130 & 2.67 & -0.41 & 0.43 & 0.24 & 0.20 \\
$\mathrm{Ni}$ & 1.104 & 3.0 & -0.35 & 0.49 & 0.30 & 0.40 \\
$\mathrm{Mo}$ & 1.126 & 2.57 & -0.64 & 1.15 & 0.96 & 0.09 \\
$\mathrm{Ru}$ & 1.141 & 2.61 & -0.51 & 0.36 & 0.17 & 0.16 \\
$\mathrm{Rh}$ & 1.123 & 2.90 & -0.39 & 0.45 & 0.26 & 0.26 \\
\hline \hline
\end{tabular}

we got significantly smaller activation barrier $0.36 \mathrm{eV}$, for weakly chemisorbed methane on $\mathrm{Ru} / \mathrm{Cu}(111) \mathrm{SAC}$. The schematic representation of methane dissociation reaction pathway, bondlength ( $\mathrm{C}-\mathrm{H}, \mathrm{Cu}-\mathrm{H}, \mathrm{Ru}-\mathrm{C})$, activation energy, and reaction energy for the active catalyst is represented in SI Fig. 2. Taking into account the ZPE correction, Ru, Co, and $\mathrm{Rh} @ \mathrm{Cu}(111)$ have the lowest activation barrier. Further, a five fold reduction in the activation barrier is observed for these SACs compared to $\mathrm{Cu}(111)$. Thus, $\mathrm{Ru}, \mathrm{Co}, \mathrm{Rh} / \mathrm{Cu}(111)$ SACs are efficient catalysts for the first $\mathrm{C}-\mathrm{H}$ bond dissociation of methane.

\section{Conclusion}

In this work, we have systematically investigated SACs doped with eighteen transition metals on $\mathrm{Cu}(111)$ surface as likely candidates for methane activation. We found that on the eighth and ninth group transition-metals doped surfaces viz., Fe, Co, Ru, and Rh possess strong $\mathrm{C}-\mathrm{H}$ bond activation with moderate adsorption energy and low activation barrier. Interpreting our results, we infer no one-to-one relation between adsorption energies and $\mathrm{C}-\mathrm{H}$ bond elongation. Our calculations suggest that $\mathrm{Ru} / \mathrm{Cu}(111)$ is a potential SAC for methane activation, based on its overall structure stability, lower endothermic state, and lower activation 
barrier with moderate adsorption energy. While $\mathrm{Rh} / \mathrm{Cu}(111)$ stands as a promising candidate, authors encourage further investigation into $\mathrm{Co} / \mathrm{Cu}(111)$, given the cheaper costs of both the constituent metals as compared to other SACs. The low chemical barrier can make methane molecules cleave at low temperatures. In light of practical applications, it would be desirable to investigate further steps for integrated activation and conversion of methane, as a source of hydrogen, direct functionalization, methanol formation, methyl sulphonic acid $\left(\mathrm{CH}_{3} \mathrm{SO}_{3} \mathrm{H}\right)$ formation, halogenation, $\mathrm{C}-\mathrm{C}$ coupling (higher hydrocarbons, aromatization) and various other unexplored avenues.

\section{Conflicts of Interests}

There are no conflicts to declare.

\section{Acknowledgements}

Authors greatfully acknowledge to CSIR-4PI for computational facility. MB thanks to UGC for the research fellowship.

\section{References}

(1) Schwach, P.; Pan, X.; Bao, X. Direct conversion of methane to value-added chemicals over heterogeneous catalysts: challenges and prospects. Chemical reviews 2017, 117, 8497-8520.

(2) Abbas, H. F.; Daud, W. W. Hydrogen production by methane decomposition: a review. International journal of hydrogen energy 2010, 35, 1160-1190.

(3) Marcinkowski, M. D.; Darby, M. T.; Liu, J.; Wimble, J. M.; Lucci, F. R.; Lee, S.; Michaelides, A.; Flytzani-Stephanopoulos, M.; Stamatakis, M.; Sykes, E. C. H. Pt/Cu 
single-atom alloys as coke-resistant catalysts for efficient $\mathrm{C}-\mathrm{H}$ activation. Nature chemistry 2018, 10, 325 .

(4) Taccardi, N.; Grabau, M.; Debuschewitz, J.; Distaso, M.; Brandl, M.; Hock, R.; Maier, F.; Papp, C.; Erhard, J.; Neiss, C., et al. Gallium-rich Pd-Ga phases as supported liquid metal catalysts. Nature chemistry 2017, 9, 862-867.

(5) Liao, M.-S.; Zhang, Q.-E. Dissociation of methane on different transition metals. Journal of Molecular Catalysis A: Chemical 1998, 136, 185-194.

(6) Harris, J.; Simon, J.; Luntz, A. C.; Mullins, C. B.; Rettner, C. T. Thermally assisted tunneling: $\mathrm{CH}_{4}$ dissociation on $\mathrm{Pt}(111)$. Phys. Rev. Lett. 1991, 67, 652-655.

(7) Van Santen, R. A. Complementary structure sensitive and insensitive catalytic relationships. Accounts of chemical research 2009, 42, 57-66.

(8) Bunnik, B. S.; Kramer, G. J. Energetics of methane dissociative adsorption on Rh \{111\} from DFT calculations. Journal of Catalysis 2006, 242, 309-318.

(9) Bothra, P.; Pati, S. K. Improved catalytic activity of rhodium monolayer modified nickel (110) surface for the methane dehydrogenation reaction: a first-principles study. Nanoscale 2014, 6, 6738-6744.

(10) Ang, M.; Miller, J.; Cui, Y.; Mo, L.; Kawi, S. Bimetallic Ni-Cu alloy nanoparticles supported on silica for the water-gas shift reaction: activating surface hydroxyls via enhanced CO adsorption. Catalysis Science \& Technology 2016, 6, 3394-3409.

(11) Gabrienko, A. A.; Arzumanov, S. S.; Toktarev, A. V.; Danilova, I. G.; Prosvirin, I. P.; Kriventsov, V. V.; Zaikovskii, V. I.; Freude, D.; Stepanov, A. G. Different efficiency of $\mathrm{Zn} 2+$ and $\mathrm{ZnO}$ species for methane activation on Zn-modified zeolite. ACS Catalysis 2017, \%, 1818-1830. 
(12) Rosen, A. S.; Notestein, J. M.; Snurr, R. Q. Structure-Activity Relationships That Identify Metal-Organic Framework Catalysts for Methane Activation. ACS Catalysis 2019, 9, 3576-3587.

(13) Fung, V.; Tao, F. F.; Jiang, D.-e. Low-temperature activation of methane on doped single atoms: descriptor and prediction. Physical Chemistry Chemical Physics 2018, 20, 22909-22914.

(14) Righi, G.; Magri, R.; Selloni, A. Methane Activation on Metal-Doped (111) and (100) Ceria Surfaces with Charge-Compensating Oxygen Vacancies. The Journal of Physical Chemistry C 2020, 124, 17578-17585.

(15) Varghese, J. J.; Trinh, Q. T.; Mushrif, S. H. Insights into the synergistic role of metallattice oxygen site pairs in four-centered $\mathrm{C}-\mathrm{H}$ bond activation of methane: the case of CuO. Catalysis Science \& Technology 2016, 6, 3984-3996.

(16) Wan, Q.; Fung, V.; Lin, S.; Wu, Z.; Jiang, D.-e. Perovskite-supported Pt single atoms for methane activation. Journal of Materials Chemistry A 2020, 8, 4362-4368.

(17) Yang, X.-F.; Wang, A.; Qiao, B.; Li, J.; Liu, J.; Zhang, T. Single-atom catalysts: a new frontier in heterogeneous catalysis. Accounts of chemical research 2013, 46, 1740-1748.

(18) Righi, G.; Magri, R.; Selloni, A. Methane Activation on Metal-Doped (111) and (100) Ceria Surfaces with Charge-Compensating Oxygen Vacancies. The Journal of Physical Chemistry C 2020, 124, 17578-17585.

(19) Liang, Z.; Li, T.; Kim, M.; Asthagiri, A.; Weaver, J. F. Low-temperature activation of methane on the IrO2 (110) surface. Science 2017, 356, 299-303.

(20) Liu, Y.-C.; Yeh, C.-H.; Lo, Y.-F.; Nachimuthu, S.; Lin, S. D.; Jiang, J.-C. In situ spectroscopic and theoretical investigation of methane activation on $\mathrm{IrO} 2$ nanoparticles: Role of Ir oxidation state on C-H activation. Journal of Catalysis 2020, 385, 265-273. 
(21) Blöchl, P. E. Projector augmented-wave method. Physical review B 1994, 50, 17953.

(22) Kresse, G.; Joubert, D. From ultrasoft pseudopotentials to the projector augmentedwave method. Physical review b $\mathbf{1 9 9 9 , 5 9 , 1 7 5 8 .}$

(23) Perdew, J. P.; Burke, K.; Ernzerhof, M. Generalized gradient approximation made simple. Physical review letters 1996, 77, 3865.

(24) Perdew, J. P.; Burke, K.; Ernzerhof, M. Generalized Gradient Approximation Made Simple [Phys. Rev. Lett. 77, 3865 (1996)]. Physical Review Letters 1997, 78, 13961396.

(25) Kresse, G.; Hafner, J. Ab initio molecular-dynamics simulation of the liquid-metalamorphous-semiconductor transition in germanium. Physical Review B 1994, 49, 14251.

(26) Kresse, G.; Furthmüller, J. Efficient iterative schemes for ab initio total-energy calculations using a plane-wave basis set. Physical review B 1996, 54, 11169.

(27) Kresse, G.; Furthmüller, J. Efficiency of ab-initio total energy calculations for metals and semiconductors using a plane-wave basis set. Computational materials science 1996, $6,15-50$.

(28) Straumanis, M.; Yu, L. Lattice parameters, densities, expansion coefficients and perfection of structure of $\mathrm{Cu}$ and of $\mathrm{Cu}-\mathrm{In} \alpha$ phase. Acta Crystallographica Section A: Crystal Physics, Diffraction, Theoretical and General Crystallography 1969, 25, 676-682.

(29) Larsen, A. H.; Mortensen, J. J.; Blomqvist, J.; Castelli, I. E.; Christensen, R.; Dułak, M.; Friis, J.; Groves, M. N.; Hammer, B.; Hargus, C., et al. The atomic simulation environment - a Python library for working with atoms. Journal of Physics: Condensed Matter 2017, 29, 273002. 
(30) Henkelman, G.; Uberuaga, B. P.; Jónsson, H. A climbing image nudged elastic band method for finding saddle points and minimum energy paths. The Journal of chemical physics 2000, 113, 9901-9904.

(31) Henkelman, G.; Jónsson, H. Improved tangent estimate in the nudged elastic band method for finding minimum energy paths and saddle points. The Journal of chemical physics 2000, 113, 9978-9985.

(32) Henkelman, G.; Jónsson, H. A dimer method for finding saddle points on high dimensional potential surfaces using only first derivatives. The Journal of chemical physics 1999, 111, 7010-7022.

(33) Dronskowski, R.; Blöchl, P. E. Crystal orbital Hamilton populations (COHP): energyresolved visualization of chemical bonding in solids based on density-functional calculations. The Journal of Physical Chemistry 1993, 97, 8617-8624.

(34) Deringer, V. L.; Tchougréeff, A. L.; Dronskowski, R. Crystal orbital Hamilton population (COHP) analysis as projected from plane-wave basis sets. The journal of physical chemistry A 2011, 115, 5461-5466.

(35) Maintz, S.; Deringer, V. L.; Tchougréeff, A. L.; Dronskowski, R. Analytic projection from plane-wave and PAW wavefunctions and application to chemical-bonding analysis in solids. Journal of computational chemistry 2013, 34, 2557-2567.

(36) Maintz, S.; Deringer, V. L.; Tchougréeff, A. L.; Dronskowski, R. LOBSTER: A tool to extract chemical bonding from plane-wave based DFT. Journal of Computational Chemistry 2016, 37, 1030-1035.

(37) Qin, F.; Chen, W. Copper-based single-atom alloys for heterogeneous catalysis. Chemical Communications 2021, 57, 2710-2723. 
(38) Hwu, H. H.; Chen, J. G. Surface chemistry of transition metal carbides. Chemical reviews 2005, 105, 185-212.

(39) Nørskov, J. K.; Abild-Pedersen, F.; Studt, F.; Bligaard, T. Density functional theory in surface chemistry and catalysis. Proceedings of the National Academy of Sciences 2011, 108, 937-943.

(40) Marcinkowski, M. D.; Darby, M. T.; Liu, J.; Wimble, J. M.; Lucci, F. R.; Lee, S.; Michaelides, A.; Flytzani-Stephanopoulos, M.; Stamatakis, M.; Sykes, E. C. H. Pt/Cu single-atom alloys as coke-resistant catalysts for efficient $\mathrm{C}-\mathrm{H}$ activation. Nature chemistry 2018, 10, 325-332.

(41) Ciobica, I.; Frechard, F.; Van Santen, R.; Kleyn, A.; Hafner, J. A DFT study of transition states for $\mathrm{C}-\mathrm{H}$ activation on the $\mathrm{Ru}$ (0001) surface. The Journal of Physical Chemistry B 2000, 104, 3364-3369. 